\title{
B-natriuretic peptide concentrations had high sensitivity and specificity for detecting abnormal ventricular function
}

Krishnaswamy P,Lubien E, Clopton P, et al. Utility of B-natriuretic peptide levels in identifying patients with left ventricular systolic or diastolic dysfunction. Am J Med 2001 Sep;111:274-9.

\section{QUESTION: In patients referred for echocardiography, what are the diagnostic properties of B-natriuretic peptide (BNP) concentrations for detecting abnormal ventricular function?}

Source of funding: no external funding.

For correspondence: $D r$ A S Maisel, VAMC Cardiology 111-A, San Diego, CA, USA. amaisel@ucsd.edu.

\section{Design}

Blinded comparison of BNP concentration with the results of echocardiography as the diagnostic standard.

\section{Setting}

San Diego Veteran's Healthcare System, California, USA.

\section{Patients}

400 patients (mean age $67 \mathrm{y}, 96 \%$ men) who were referred for echocardiography to evaluate left ventricular function. Patients whose referral was to assess valve disease or to rule out vegetation or cardioembolic stroke were excluded.

Description of test and diagnostic standard The BNP concentration in blood samples from all patients was measured using the Triage B-type natriuretic fluorescence immunoassay (Biosite Diagnostics, La Jolla, CA, USA). All patients were scanned with 2-dimensional echocardiography using commercially available instruments that operate at 2.0 to $3.5 \mathrm{mHz}$; the scans were done in standard fashion in parasternal longand short-axis views and apical 2- and 4-chamber views. Experienced cardiologists (blinded to the BNP concentrations) interpreted the echocardiographic results and grouped the patients into those with normal ventricular function (ejection fraction $>50 \%$, with no major wall-motion abnormalities and no evidence of impaired or restrictive haemodynamics) and those with abnormal ventricular function (ejection fraction $<50 \%$; a regional wall-motion abnormality; or an impaired relaxation, restrictive, or pseudonormal pattern of left ventricular filling).

\section{Main outcome measures}

Sensitivity, specificity, and positive and negative likelihood ratios.

\section{Main results}

$63 \%$ of patients had abnormal left ventricular function. Sensitivity, specificity, and positive and negative likelihood ratios for several cut points of BNP concentrations are shown in the table. The area under the receiver-operating characteristic curve was 0.95 (95\% CI, 0.93 to 0.97 ).

\section{Conclusion}

In patients referred for echocardiography, B-natriuretic peptide concentration (cut points 49 to $75 \mathrm{pg} / \mathrm{ml}$ ) had high sensitivity and specificity for detecting abnormal ventricular function.
Diagnostic properties of B-natriuretic peptide concentrations for detecting abnormal ventricular function*

\begin{tabular}{cllll} 
Cut points $(\mathrm{pg} / \mathrm{ml})$ & Sensitivity $(95 \% \mathrm{Cl})$ & Specificity (Cl) & +LR & -LR \\
\hline 345 & $36 \%(30$ to 42$)$ & $99 \%(96$ to 100$)$ & 36.00 & 0.65 \\
\hline 160 & $65 \%(59$ to 71$)$ & $99 \%(97$ to 100$)$ & 65.00 & 0.35 \\
\hline 110 & $75 \%(69$ to 80$)$ & $98 \%(94$ to 99$)$ & 37.50 & 0.26 \\
\hline 75 & $85 \%(80$ to 89$)$ & $97 \%(93$ to 99$)$ & 28.33 & 0.15 \\
\hline 62 & $89 \%(84$ to 92$)$ & $90 \%(85$ to 94$)$ & 8.90 & 0.12 \\
\hline 49 & $91 \%(87$ to 94$)$ & $82 \%(74$ to 87$)$ & 5.06 & 0.11 \\
\hline
\end{tabular}

*Diagnostic terms defined in glossary; Cls and LRs calculated from data in article.

\section{COMMENTARY}

The study by Krishnaswamy $e t a l$ is the most recent in a series of studies attempting to find a clinically useful measure of left ventricular dysfunction in a world of increasing technology but diminishing access. The utility of such a test is clear: a simple, sensitive, and specific test would obviate the need for routine echocardiograms.

Krishnaswamy et al tested the use of BNP concentrations in patients referred for echocardiograms and correlated these concentrations with blinded assessment of the echocardiographic results. The study results are impressive, and the table of likelihood ratios could be useful; however, a number of concerns exist that should be addressed before the BNP test can be used routinely.

First, this test was evaluated in a specific population: patients with suspected congestive heart failure (CHF). In order to validate the test, it should be applied to a wider population of patients to confirm that BNP concentrations are only elevated in those with CHF to the degree shown in the study. Some evidence exists that BNP concentrations are also elevated in patients with corpulmonale secondary to lung disease. Ishii $e t$ $a l^{2}$ examined BNP in postinfarction patients in a general practice setting and did not find the discriminatory power found in the study by Krishnaswamy $e t$ al.

Second, a concern exists about the effects of medications on BNP concentrations. Angiotensin-converting enzyme inhibitors do not seem to affect BNP concentrations, but $\beta$-blockers do. It is not clear whether this effect was seen in the Krishnaswamy study, but if such an effect existed it could also confound the generalisability of these results. These 2 concerns need to be addressed before adopting this simple test for widespread use. Another interesting issue would be to see whether this test can be augmented by other such bedside tests as the Valsalva manoeuvre with systolic ausculatory excursion to strengthen its utility.

Neil Gibson, MSc, MD University of Alberta Edmonton, Alberta, Canada

1 Ishii J, Nomura M, Ito M, et al. Plasma concentration of brain natriuretic peptide as a biochemical marker for the evaluation of right ventricular overload and mortality in chronic respiratory disease. Clin Chim Acta 2000;301:19-30.

2 McClure SJ, Caruana L, Davie AP, et al. Cohort study of plasma natriuretic peptides for identifying left ventricular systolic dysfunction in primary care. BMJ 1998;317:516-9.

3 Hara Y, Hamada M, Shigematsu Y, et al. Effect of beta-blocker on left ventricular function and natriuretic peptides in patients with chronic heart failure treated with angiotensinconverting enzyme inhibitor.Jpn Circ J 2000;64:365-9. 